\title{
Two Hybrid Approaches to Fatigue Modeling of Advanced-Sheet Molding Compounds (A-SMC) Composite
}

\author{
H. Ayari ${ }^{1,2} \cdot$ J. Fitoussi $^{1} \cdot$ A. Imaddahen ${ }^{1} \cdot$ S. Tamboura ${ }^{2} \cdot$ M. Shirinbayan ${ }^{1}$ • \\ H. Ben Dali ${ }^{2} \cdot$ A. Tcharkhtchi ${ }^{1}$
}

\begin{abstract}
To reinforce the environmental standards, we need to strengthen the lightening of vehicles and to generalize new composite materials in order to reduce weight. To use these innovative composite materials in the mass production of automotive parts, it is essential to propose a predictive approach of the S-N curves, which must be established for each new composite formulation and for several types of microstructure within real components. Although these preliminary characterizations consume time and money, this paper proposes two hybrid methodologies to predict the fatigue life during the fatigue test. Both methodologies are based on micromechanical modeling which is developed under monotonous loading with fatigue effects under different amplitudes. The suggested methodology is based on an experimental analysis of monotonic behavior under fatigue loading and on multi-scale modeling of damage. In the results, the proposed model and the used approaches are in good agreement with the experimental results.
\end{abstract}

Keywords SMC $\cdot$ Fatigue $\cdot$ Micromechanical modeling

\section{Introduction}

Advanced Sheet Molding Compounds (A-SMCs) are materials typically formulated to meet customer requirements. They exhibit a lot of desirable characteristics, excellent chemical resistance and tensile strength, as well as cost competitiveness. For an effective design, several types of damage must be considered by manufacturers during dimension calculation. Fatigue loading may be one of the most critical failure modes that strongly affects the component life.

The direct calculation of the behavior of these structures raise important difficulties, essentially due to the great number of mechanical characteristics to be considered. The origin of these

\section{H. Ayari}

houssem.ayari@ensam.eu 
difficulties is in the anisotropy and heterogeneity of these materials. On the other hand, there are still obstacles to the industrial use of fiber-reinforced organic composites, such as the lack of knowledge of the links between the microstructure and macroscopic properties, the prediction of the damage evolution, and the realization of structural calculations adapted to this type of materials.

For a composite part subjected to repeated loading, engineers often face many difficulties because of the lack of information on the mechanical behavior, especially the damage mechanisms. Thus, it is essential to develop rapid methodologies for pre-dimensioning composite structures, which allows quickly identifying the appropriate material formulation for each component in the automobile. These methodologies must therefore be pragmatic to meet industrial needs. For components subjected to fatigue loading, this is a critical problem because of the long and costly experimental campaigns required to establish S-N curves. Indeed, the mechanical properties of these materials strongly depend on their composition [1]: the type of matrix (thermoplastic or thermosetting), the volume fraction of the reinforcement phase, the geometry, and the spatial distribution [2-11].

Therefore, due to the complexity of the local mechanisms involved in loading, the chosen approaches should be based on a very good knowledge of these different phenomena. For composites reinforced by short fibers, like the Sheet Molding Compound (SMC), it has been widely demonstrated that local damage begins at the fiber matrix interface [12, 13].

However, for fatigue behavior, the effects of load conditions (stress ratio [14, 15], cycling frequency $[16,17])$ are very importance. Hence, the chosen methodologies should be adapted to predict the life of these materials in different complex conditions.

The existing predictive fatigue models are generally classified into three categories $[6,18$, 19]: an empirical model based on S-N curves (macroscopic resistance), a phenomenological model based on residual resistance, and a micromechanical model based on the description of the mechanisms of microscopic damage.

Great efforts have been made to develop new methods that significantly reduce the cost and time spent on characterizing fatigue behavior [20-26].

Jain et al. $[27,28]$ proposed an approach based on a micromechanical model associating the state of macroscopic damage under a quasi-static load to the state of macroscopic damage reached at a certain point of the $\mathrm{S}-\mathrm{N}$ curve. The authors suggested a methodology to predict the S-N curves for other composite microstructures from the knowledge of the "master curve" which corresponds to the S-N curve established for a specific microstructure taken as a reference [29].

Jain et al. developed a new approach called the "master" S-N curve [30] based on a master Wöhler curve, from which Wöhler curves could be reconstructed for other microstructures by linking damage at the microscopic scale with macroscopic fatigue properties. Such a model required the establishment of a "master" S-N curve while considering a reference microstructure.

Guo et al. [31-35] proposed a constitutive model for the micromechanical damage to the SMC composite under monotonic loading. Le Pen et al. [36] developed a Mori-Tanaka model that included a law on damage caused by fibers in composite fatigue.

In this article, two modeling approaches applied on an A-SMC composite under fatigue loading. In order to take into consideration the microstructure and effect of damage, the model suggested in this paper relies, among other things, on the model of Jendli et al. [37], presented in the following. This model was developed in the context of damage to SMC materials under rapid stress. The main interest of this model is the integration of local damage mechanisms experimentally observed in the micromechanical model. The model proposed in this study integrates the damage to fiber / matrix interfaces as a predominant phenomenon responsible for the macroscopic damage to the material. The state of damage is reflected by several 
populations of heterogeneities at the local scale including micro-cracks. Thus, it makes it possible to get as close as possible to the macroscopic real behavior of the material. This model is based on an approach of Mori and Tanaka [38], where the phenomenon of cracking the fiber / matrix interface was integrated at the local scale.

\subsection{Material Description and Methods of Analysis}

A-SMCs consist of a vinyl ester resin reinforced with glass fibers and filled with calcium carbonate fillers $\left(\mathrm{CaCO}_{3}\right)$. The glass fibers have a weight content of $50 \%$ and are in the form of bundles. Each bundle contains about 250 fibers. These fibers have a length of $25 \mathrm{~mm}$ with a diameter of about $15 \mu \mathrm{m}$. The families of fibers that have the same volume fraction and orientation have been defined.

In this study, the materials are provided by Plastic Omnium auto exterior services. Samples are prepared in the dimension, which is shown in Fig. 1. For more details, the manufacturing process was discussed in the article of Shirinbayan [39].

Two types of A-SMC materials from the same prepreg are studied: One microstructure is "Highly Oriented" (HO) and the other one is "Randomly Oriented" (RO). For HO samples, the tests are carried out according to two main directions: the longitudinal direction (or $0^{\circ}$ ) corresponding to the direction of the creep during the hot compression, and the transverse direction $\left(90^{\circ}\right)$ corresponding to the perpendicular direction.

The experimental database required to establish the hybrid model is derived from the following mechanical tests:

- First, tensile tests to failure.

- Second, quasi-static (strain rate of $2 \mathrm{~mm} / \mathrm{min}$ ) loading-unloading tests with progressive increase in the maximum loading at each cycle to failure. All the performed tests define the minimum stress at the reloading, which is equal to $10 \%$ of the last reached maximum stress.

- Third, tension-tension fatigue tests $(\mathrm{R}=0.1, \mathrm{f}=10 \mathrm{~Hz})$ up to failure for different maximum-load levels. All fatigue tests are preceded by an elastic loading-unloadingreloading cycle, which allows for a more precise determination of Young's $\mathrm{E}_{0}$ and $\mathrm{E}_{1}$ moduli. Both latter respectively correspond to the stiffness of undamaged material and the residual stiffness after the first cycle.

The analysis of these three types of tests respectively gives access to the following data:

- Tensile-to-failure curves that particularly permit the identification of the failure stresses for each configuration;

- Loss-stiffness curves as a function of the applied loading, whose main objective is to trace the relative decrease in stiffness as a function of the applied loading;

- Stiffness reduction curves according to the applied cycles and the Wöhler curves.

- Through these results and using our micromechanical model, we can implement our methodologies.

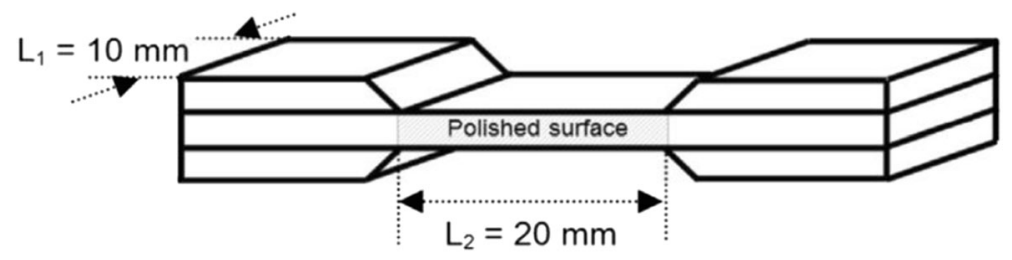

Fig. 1 Specimen dimension obtained from optimized procedure results 
These tests are performed within the framework of the Ph.D. of Shirinbayan [40].

\subsection{Micromechanical Modeling}

The chosen model can be divided into three essential phases:

The estimation of the global rigidity tensor of the material from the properties of the various constituents, using the average field approach proposed by Mori and Tanaka, is coupled with Eshelby's equivalent inclusion model. Therefore, the field of stress, which is local and around inclusion, is estimated and it enables identifying normal and tangential interfacial stresses. A criterion of local damage (estimation and quantification of the density of interfacial cracks) and a law of damage evolution are integrated. Global behavior is modeled through the integration of the initial anisotropy caused by the presence of reinforcements and its evolution due to damage.

The equations of the micromechanical model are recalled in what follows. These equations present the theoretical framework for estimating the overall mechanical behavior of the material as well as the local constraints at the fiber-matrix interface.

Using the Mori-Tanaka theory, adopted later by Benvensite [40], we manage to predict the overall three-dimensional effective rigidity tensor of the staple fiber composite material as well as the average stress fields inside and outside reinforcements at the level of the matrix [36]. The reinforcement is modeled as an ellipsoidal inclusion and is characterized by its slenderness (length/diameter) and isotropic elastic properties. The reinforcements, which are present as inclusions, are transformed into an equivalent matrix thanks to the Eshelby tensor reformulated and readapted by Mura [41]. This tensor is necessary for the identification of the overall rigidity of the composite.

Eshelby's equivalent inclusion techniques [42] and classical homogenization methods lead to the formulation of the overall rigidity tensor (Eq. 1.1):

$$
C^{C o m p}=C^{m}\left[I+f\langle\mathbf{Q}\rangle(I+f\langle(S-I) \mathbf{Q}\rangle)^{-1}\right]^{-1}
$$

where $C^{m}$ and $S$ are respectively the rigidity tensor of the matrix and Eshelby's tensor, $f$ is the volumetric fraction of reinforcement, and $Q$ presents the average value of the "pseudo-tensor of localization" defined for each family of reinforcement $i$ whose expression is as follows:

$$
\mathrm{Q}^{i}=\left(\left(C^{m}-C^{i}\right)\left(S^{i}-I\right)-C^{i}\right)^{-1}\left(C^{i}-C^{m}\right)
$$

where $S^{i}$ presents Eshelby's tensor of the $\mathrm{i}^{\text {th }}$ reinforcement family which depends on the mechanical properties of the matrix and the spatial arrangement and geometry of reinforcement, and tensor $C^{i}$ represents the rigidity of families of reinforcement marked by index $i$.

For A-SMCs, a family of reinforcement is distinguished by its orientation in the plane. Different work [42-44] treated the stress discontinuity at a leap in the fiber/matrix interface. When loading the material with macroscopic stress $\Sigma$, the matrix phase remains isotropically elastic, so it is necessary to calculate stress at the level of all points of the interface.

$$
\sigma^{i}=C^{m}\left(I+\left(S^{i}-I\right) \mathbf{Q}^{i}\right)(I+f\langle(S-I) \mathrm{Q}\rangle) C^{m^{-1}} \sum
$$



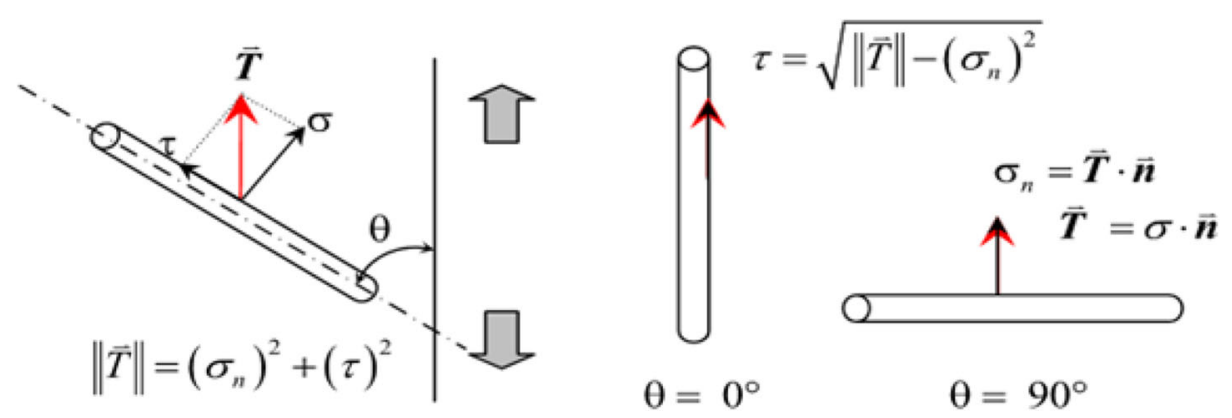

Fig. 2 Stress exerted on fiber as a function of its orientation, $\theta\left(^{\circ}\right)$ relative to direction of loading

By adopting the condition of the continuity of normal stress during the transition between the fiber and the matrix, we can then deduce its expression at the interface. As a function of stress in the fiber (Eq. 1.3), normal stress at the interface will therefore have the following form:

$$
\sigma_{n}=\vec{T} \cdot \vec{n}
$$

With Eqs. 1.3 and 1.4, we get:

$$
\begin{gathered}
\overrightarrow{\mathrm{T}}=\sigma^{\mathrm{i}} \cdot \overrightarrow{\mathrm{n}} \\
\tau^{i}=\sqrt{\|\vec{T}\|-\left(\sigma_{n}\right)^{2}}
\end{gathered}
$$

where $\overrightarrow{\mathrm{n}}$ is the normal vector at the considered point of the interface (Fig. 2).

The interfacial failure probability for each fiber orientation family $\theta i$ is given by:

$$
P_{r}(\theta, \varphi)=1-\exp \left(-\left(\left(\frac{\sigma}{\sigma_{0}}\right)^{2}+\left(\frac{\tau}{\tau_{0}}\right)^{2}\right)^{m}\right)
$$

where $m$ is a material parameter related to the scatter of microstructure, and normal stress $\sigma$ and shear stress $\tau$ depend on the macroscopic stress, the fiber orientation, the volume fraction, the aspect ratio of the fiber, the elastic properties of the matrix, and the fiber.

As a consequence, at each $\mathbf{n}$ calculation step, local interface failure probabilities are calculated and they give access to the amounts of the remaining active fiber $\mathbf{f}_{\mathbf{n}}^{\text {act }}$. This includes the volume fraction of undamaged fibers $\mathbf{f}_{\mathbf{n}}^{\mathbf{N D}}$, the part of the debonded fiber which continues participating in composite reinforcement, and the micro-cracks volume fraction to be introduced. Therefore, the local damage state is described at each $\mathbf{n}$ step by the following equations:

$$
\begin{gathered}
f_{n}^{N D}=\left(1-P_{r}^{n}\right) * \mathrm{f}_{n-1}^{N D} \\
f_{n}^{a c t}=f_{n}^{N D}+k \sum_{i=1}^{n} P_{r}^{i} \cdot f_{i-1}^{N D} \rrbracket
\end{gathered}
$$




$$
f_{n}^{m c}=f_{n-1}^{m c}+h \cdot P_{r}^{n} \cdot f_{n-1}^{N D}
$$

where $k$ is a reduction coefficient applied to partially debonded fibers. This parameter is evaluated by finite-element calculations performed on a representative cell containing a partially debonded fiber and is equal to 0.9 . Moreover, $h$ is the ratio between the volume of the introduced penny shape (representing an interfacial microcrack) and the fiber evaluated by geometric considerations.

\subsection{Implementation of First Method}

The proposed model combines two types of approaches, phenomenological and micromechanical, to take advantage of each of them. The objective is to seek an optimal compromise between the industrial applicability of the predictive model used and the relevance of the description of the physical phenomena taken into account while requiring only a limited number of experimental data.

Consequently, this model must demonstrate its ability to rapidly produce lifetime predictions by requiring only a limited number of tests. Hence, the duration of the optimization cycle of the material and the pre-dimensioning phase will be shortened.

This suggested methodology relies also on the experimental analysis and micromechanical modeling of monotonic behavior in order to predict fatigue life under loading. Unlike the second approach, the intrinsic relationship between the two types of loading is microscopically evaluated. The proposed approach is based on the following considerations:

- When we notice a decrease in stiffness, it is directly related to the overall density of microcracks present in the material. Thus, there is a mathematical relationship that links these two magnitudes.

- In addition, the increase in the crack density leads to a reduction in the resistant surface (see the global theory of damage). When this resistant surface becomes too small, the existing cracks catastrophically coalesce, which results in a break in the Representative Elementary Volume (REV). The latter is therefore attained when the overall density of crack "d", considered as a local indicator of damage, reaches a critical value " $\mathrm{d}_{\mathrm{c}}$ ".

Accordingly, it seems natural to propose a criterion of break in the REV based on a value of critical microscopic damage: When the " $\mathrm{d}_{\mathrm{c}}$ " value is reached, the density of cracks is such that the resistant surface is no longer enough and there is a break in the REV.

In this second approach, we propose to establish a state equation connecting a local damage rate $\left(d / d_{c}\right)$ to the rate of macroscopic damage (relative stiffness decrease $E / E_{0}$ ). As already expressed, we suppose that this equation, established under monotonous loading, can be also exploited under cyclic loading.

This hypothesis, which forms the basis of our approach, leans on the fact that the same phenomena of damage are observed for both types of loading. Generally, the same states of damage are found during these two types of loading.

When damage at the microscopic and macroscopic scales is expressed in a relative value, the intrinsic relation should also be relatively independent of the microstructure. In other words, we assume that two composite samples with equivalent relative rigidity loss, by 
applying a monotonic load (for the first one) and a fatigue load (for the second one), are subjected to an equivalent local damage rate.

Final failure occurs when the micro crack density reaches a certain critical value [36, 44]. This value can be represented as a local damage rate, $d / d_{c}$, where $d$ is related to the damage density at the fiber-matrix interface and dc is the maximum critical value. For SMC composite materials, the phenomenon of pseudo-delamination, which always appears just before breaking $[38,45,46]$, can occur when this local damage rate is equal to 1 :

$$
\mathrm{d} / \mathrm{d}_{\mathrm{c}}=1
$$

The whole methodology is represented schematically in Fig. 3.

The four steps for predicting the Wohler curve are as follows:

First step: The micromechanical model described above makes it possible to predict the evolution of the properties of the equivalent homogeneous material. As a result, we can easily trace the evolution of the progressive reduction in rigidity during a tensile test. The key question of the micromechanical model lies in the identification of the failure criterion parameters of the local fiber-matrix interface. The latter is identified by reverse engineering based on 0 and $90^{\circ}$ results. They are then validated on the other orientations. The results of the decrease in simulated stiffness compared to the experiments are shown in Fig. 4. A power function can be chosen to represent the average evolution of the loss of rigidity. The relative rigidity loss during a tensile load can be expressed by:

$$
\frac{E}{E_{0}}=\left(\frac{\sigma}{\sigma_{s}}\right)^{b} \text { for } \sigma \geq \sigma S
$$

where $\sigma_{\mathrm{S}}$ is the threshold stress, $\mathrm{b}$ is a kinetic parameter, and $\sigma$ is the applied stress.

Second step: Determining an accurate local damage indicator:

The approach proposed in this article is based on the definition of a local damage indicator. Its critical value corresponds to a state of critical damage leading to the ruin of the material. Thus, the definition of the local indicator of damage $d$ and its associated critical value $d_{c}$ should be

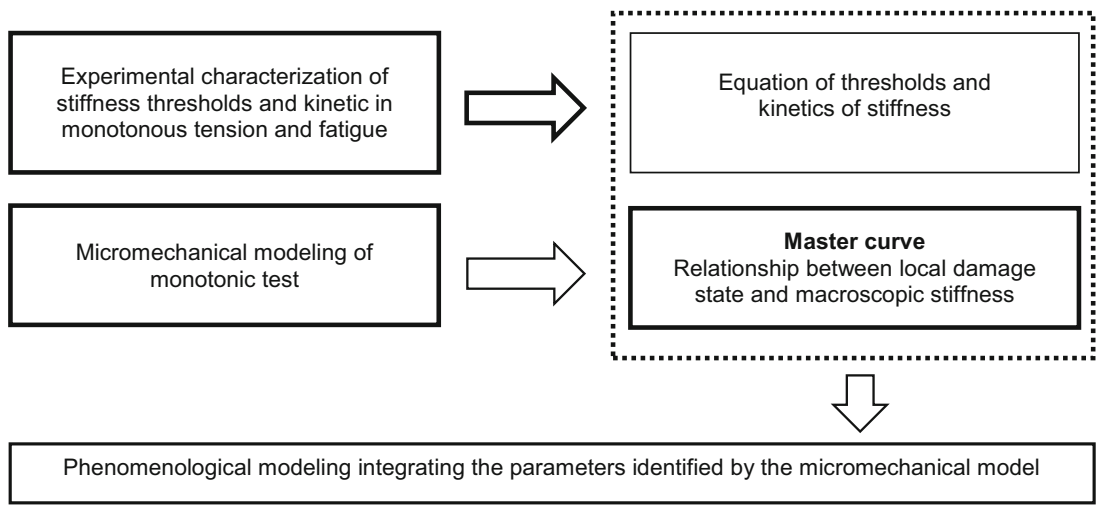

Fig. 3 Presentation of first proposed method 


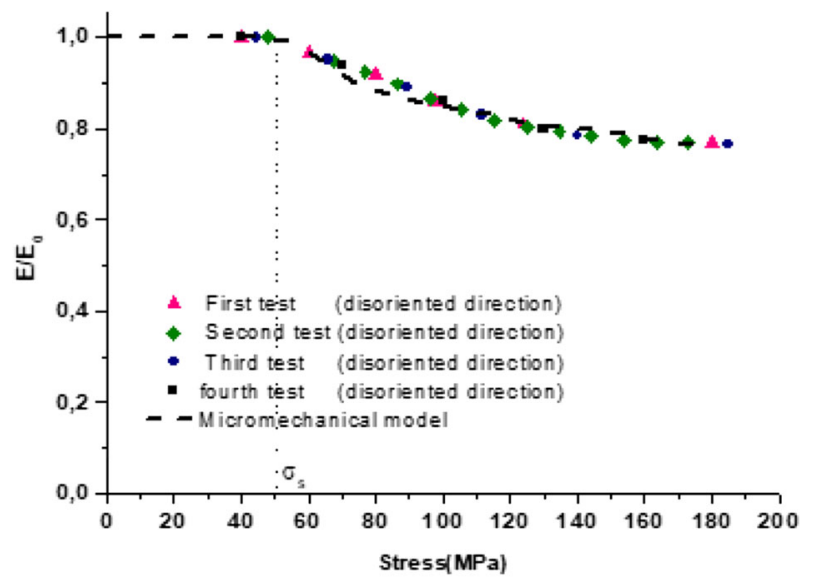

Fig. 4 Comparison between simulation and model: RO-A-SMC

related to the local parameters describing the state of local damage, namely the micro-crack density $\mathrm{d}_{\text {glob }}$ and the remaining active fibers $\mathrm{F}_{\text {actives}}$, which are the output of micromechanical modeling.

To allow the indicator of local damage $\mathrm{d}$ be independent of the microstructure, several formulations have been proposed: $\mathrm{d}_{1}, \mathrm{~d}_{2}$ and $\mathrm{d}_{3}$. These formulations use microscopic parameters, $\mathrm{F}_{\text {actives}}, \mathrm{F}_{\mathrm{ND}}$ and $\mathrm{F}_{\mathrm{MC}}$, which are derived from micromechanical modeling and they describe the damage state of the microstructure.

$$
\begin{gathered}
\mathrm{d} 1=F_{\text {actives }} * d_{\text {glob }} \\
\mathrm{d} 2=F_{N D} * d_{g l o b} \\
\mathrm{~d} 3=F_{M C} * d_{g l o b}
\end{gathered}
$$

The chosen indicator is:

$$
\mathrm{d} 1=F_{\text {actives }} * d_{\text {glob }}
$$

Third step: Identification state equation under monotonic loading:

The micromechanical model permits tracing the evolution of the local damage rate, $d / d_{c}$ as a function of the decrease in macroscopic stiffness $E / E_{0}$ (Fig. 5). As aforementioned, this relationship is considered as a state equation linking the state of microscopic-macroscopic damage to the degradation of properties. Therefore, this relationship is believed to be accurate even for other load schemes, such as fatigue, since this relationship is independent of the 


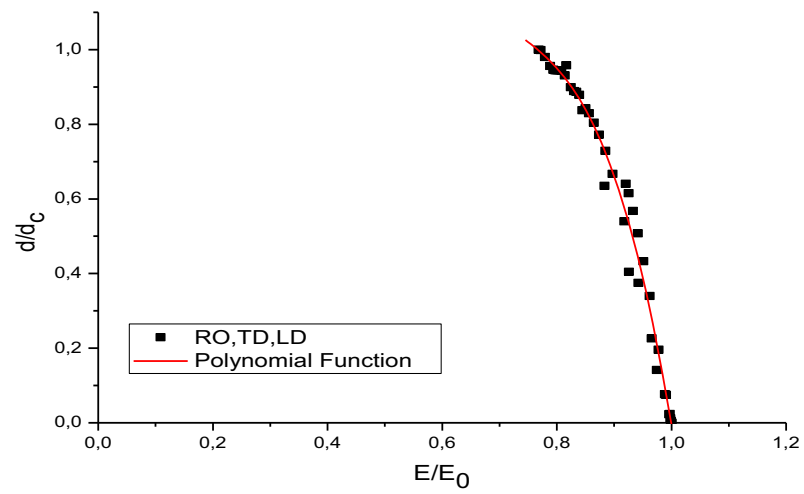

Fig. 5 Evolution of local damage rate as a function of loss in stiffness

microstructure. It is easy to describe the state equation as a polynomial function of the second degree:

$$
\frac{d}{d_{c}}=\alpha\left[\left(\frac{E}{E_{0}}\right)\right]^{2}+\beta\left[\left(\frac{E}{E_{0}}\right)\right]+\gamma
$$

where $\alpha, \beta$ and $\gamma$ are micromechanical parameters (HO-90 ${ }^{\circ} \mathrm{HO}-0^{\circ}$ and $\mathrm{RO}$ ).

Fourth step: Hybrid model and prediction of fatigue life:

The relative loss of rigidity during fatigue can be broken down into two terms:

$$
\frac{\mathrm{E}}{\mathrm{E}_{0}}=\left(\frac{\mathrm{E}}{\mathrm{E}_{1}}\right) *\left(\frac{\mathrm{E}_{1}}{\mathrm{E}_{0}}\right)
$$

The first term, $\mathrm{E} / \mathrm{E}_{1}$, is defined by the loss in fatigue stiffness:

$$
\frac{\mathrm{E}}{\mathrm{E}_{1}}=\left(\frac{\mathrm{N}}{\mathrm{N}_{\mathrm{s}}}\right)^{\mathrm{B}}
$$

If we take eq. $E / \mathrm{E}_{0}$ and integrate it into equation $\mathrm{d} / \mathrm{d}_{\mathrm{c}}$, an analytical expression of the evolution of the rate of local damage $d / d_{c}$ under loading fatigue is brought out:

$$
\frac{d}{d_{c}}=\alpha i\left[\left(\frac{E}{E_{0}}\right)\right]^{2}+\beta i\left[\left(\frac{E}{E_{0}}\right)\right]+\gamma i
$$

This expression describes the evolution of the state of the local damage $d / d_{c}$ for each considered cycle number $\mathrm{N}$ applied to the considered maximum. As defined previously, a macroscopic crack occurs when $d / d_{c}=1$ and $N=N_{r}$, where $N_{r}$ is the number of break cycles. The resolution of the preceding equation leads to the expression of the number of break cycles as a function of the applied stress: 


$$
\mathrm{N}_{\mathrm{r}}=\mathrm{N}_{\mathrm{s}} *\left[\frac{\mathrm{G}}{\left(1+\left(\frac{\sigma}{\sigma_{\mathrm{s}}}\right)^{\mathrm{b}}\right)}\right]^{\frac{1}{\mathrm{~B}}}
$$

with:

$$
\mathrm{G}=\frac{-\beta+\sqrt{\beta^{2}}-4 \alpha(\gamma-1)}{2 \alpha}
$$

This expression is used to draw the S-N curves for all microstructure configurations.

To validate our methodology, a series of fatigue tests is completed for the three microstructures. Finally, the last phase is the validation of our methodology by comparing between the experimental and digital Wöhler curves (Fig. 6).

Experience-related differences can be reduced by the good control of the experimental conditions, the refinement of the local-break criterion and the anisotropy of damage.

\subsection{Cumulative Damage Calculation}

The method is summarized in two steps:

First step: Identification of threshold parameters and damage kinetics

Our model requires the determination of three parameters: $\sigma_{\mathrm{s}}, b$ and $B$ involved in the definition of losses of stiffness under monotonic stress and fatigue:

$$
\begin{gathered}
\frac{E}{E_{0}}=\left(\frac{\sigma}{\sigma_{s}}\right)^{b} \\
\left(\frac{E}{E_{1}}\right)_{N}=\left(\frac{N}{N_{s}}\right)^{B}
\end{gathered}
$$

where $N_{s}$ presents the number of cycles from which we have a stabilization of information acquisition: It is a parameter relative to the machine. It is interesting to measure these parameters when implementing variable amplitude tests. Thus, each fatigue sequence is preceded by quasi-static loading. This allows us to identify the threshold stress value and the kinetics of stiffness $b$.

Quasi-static loading is followed by fatigue loading up to a defined number of cycles. Then, the kinetics of fatigue stiffness " $B$ " can be easily identified. Note that the relative stiffness is always determined in relation to the residual stiffness reached at the end of the previous sequence.

Second step: Establish the state equation and determinate $d / d_{c}$ 

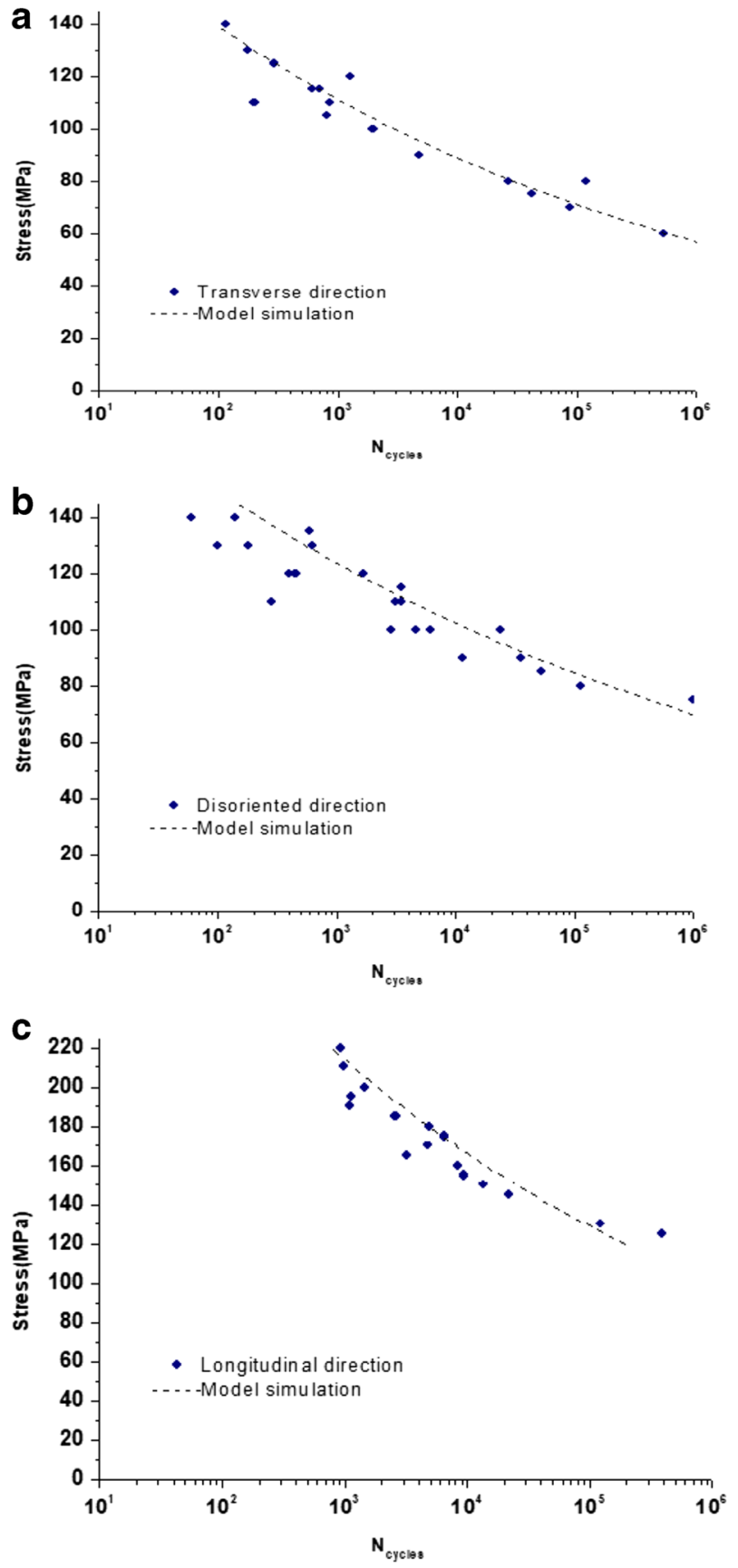

Fig. 6 Comparison between experimental-digital Wöhler curves (a) HO-90², (b) RO, and (c) HO- $0^{\circ}$

In accordance with our model, the expression of relative stiffness as a function of fatigue amplitude for each loading sequence (with a variable amplitude) can be identified as follows: 


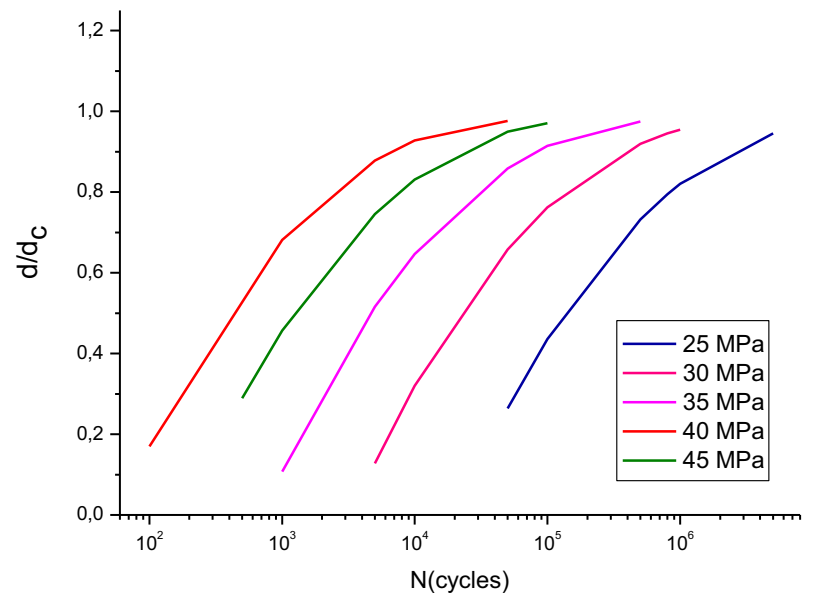

Fig. 7 Developments in $\mathrm{d} / \mathrm{d}_{\mathrm{c}}$ for different loading levels for HO- $90^{\circ}-\mathrm{A}-\mathrm{SMC}$

$$
\left(\frac{\mathrm{E}}{\mathrm{E}_{0}}\right)_{\mathrm{i}}=\left(\frac{\sigma}{\sigma_{\mathrm{s}}}\right)^{\mathrm{b}} *\left(\frac{\mathrm{N}}{\mathrm{N}_{\mathrm{s}}}\right)^{\mathrm{B}}
$$

This enables us to calculate the evolution of the relative crack density during each loading sequence $i$ :

$$
\left.\left(\frac{d}{d_{c}}\right)_{i}=\alpha i\left[\left(\left(\frac{\sigma}{\sigma_{s}}\right)^{b} *\left(\frac{N}{N_{s}}\right)^{B}\right)_{i}\right]^{2}+\beta i\left[\left(\left(\frac{\sigma}{\sigma_{s}}\right)^{b} *\left(\frac{N}{N_{s}}\right)^{B}\right)\right]_{i}\right]+\gamma i
$$

Fig. 8 Presentation of second proposed method

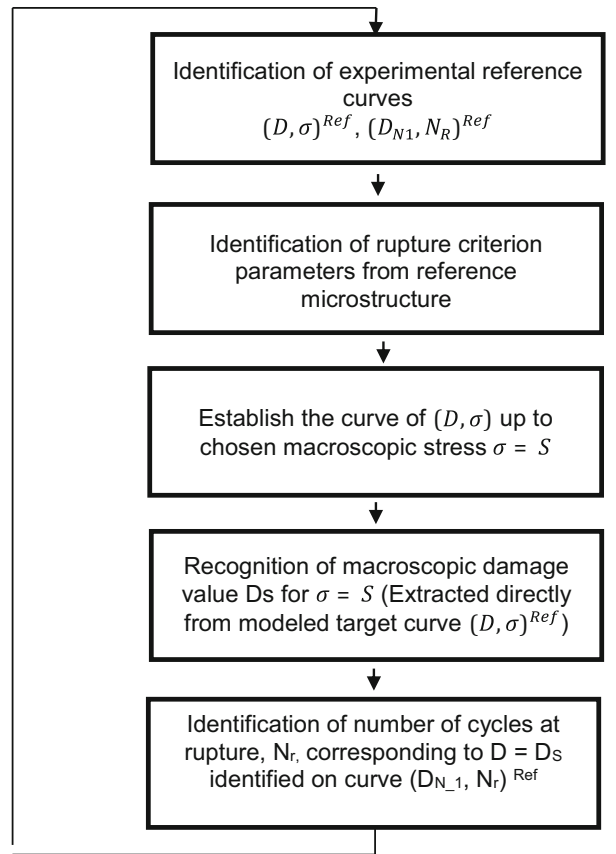


The cumulative damage state was calculated by the new model with a constant maximal applied stress chosen according to the proposed microstructure. The accumulation of damage is calculated and cumulated step by step through the calculation of the local damage rate's evolution from the relative state equation (Eq. 1.13). $\alpha, \beta$ and $\gamma$ indicate the micromechanical parameters dependent on the microstructure identified by the reverse method. The state equation $\left(d / d_{c}\right)$ shows the evolution of the rate of local damage under fatigue loading for several stress levels applied in relation to the number of cycles (Fig. 7).

This hybrid methodology converts the evolution of the decrease in phenomenological macroscopic stiffness into an indicator of local fatigue damage.

\subsection{Implementation of Second Method}

In this second approach, we use the macroscopically highlighted equivalence of damage between monotonous loading and fatigue. This methodology requires the experimental establishment of a Wöhler curve for a selected reference microstructure. The micromechanical model developed under monotonic loading then makes it possible to establish the Wöhler curves for any other targeted microstructure.

The second methodology is represented schematically in Fig. 8.

Identification of experimental reference curves

$(D, \sigma)^{R e f},\left(D_{N 1}, N_{R}\right)^{R e f}$

Identification of rupture criterion parameters from reference microstructure

Establish the curve of $(D, \sigma)$ up to chosen macroscopic stress $\sigma=S$

Recognition of macroscopic damage value Ds for $\sigma=S$ (Extracted directly from modeled target curve $\left.(D, \sigma)^{\text {Ref }}\right)$

Identification of number of cycles at rupture, $\mathrm{N}_{\mathrm{r}}$, corresponding to $\mathrm{D}=\mathrm{D}_{\mathrm{S}}$ identified on curve $\left(\mathrm{D}_{\mathrm{N} \_1}, \mathrm{~N}_{\mathrm{r}}\right)$ Ref

To perform the monotonous-fatigue coupling, we need a master curve (Fig. 9), which is the first decrease in stiffness measured during the first cycle as a function of the service life.

Once the model of micromechanical damage is identified and the (DN1, NR) curve is established using the selected reference microstructure, the following numerical procedure can be proposed to establish the S-N curve for each other targeted microstructure.

The predictive methodology for fatigue life presented above is essentially based on the following steps:

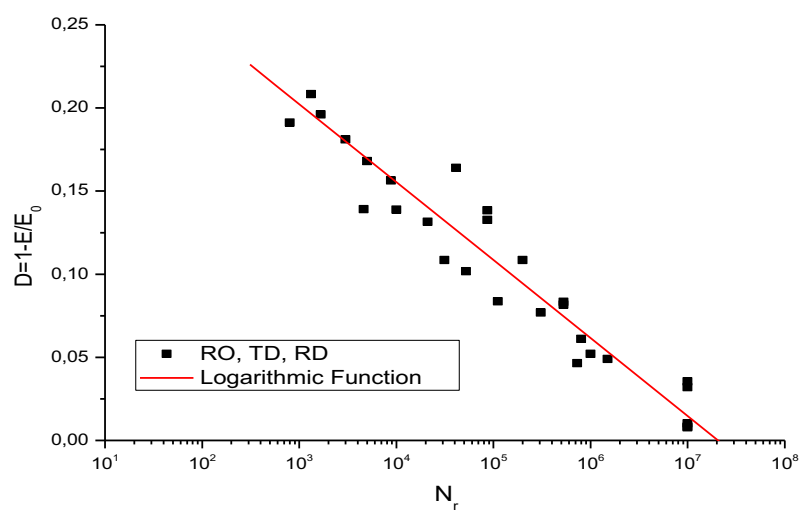

Fig. 9 Master curve linking density of crack and number of break cycles 

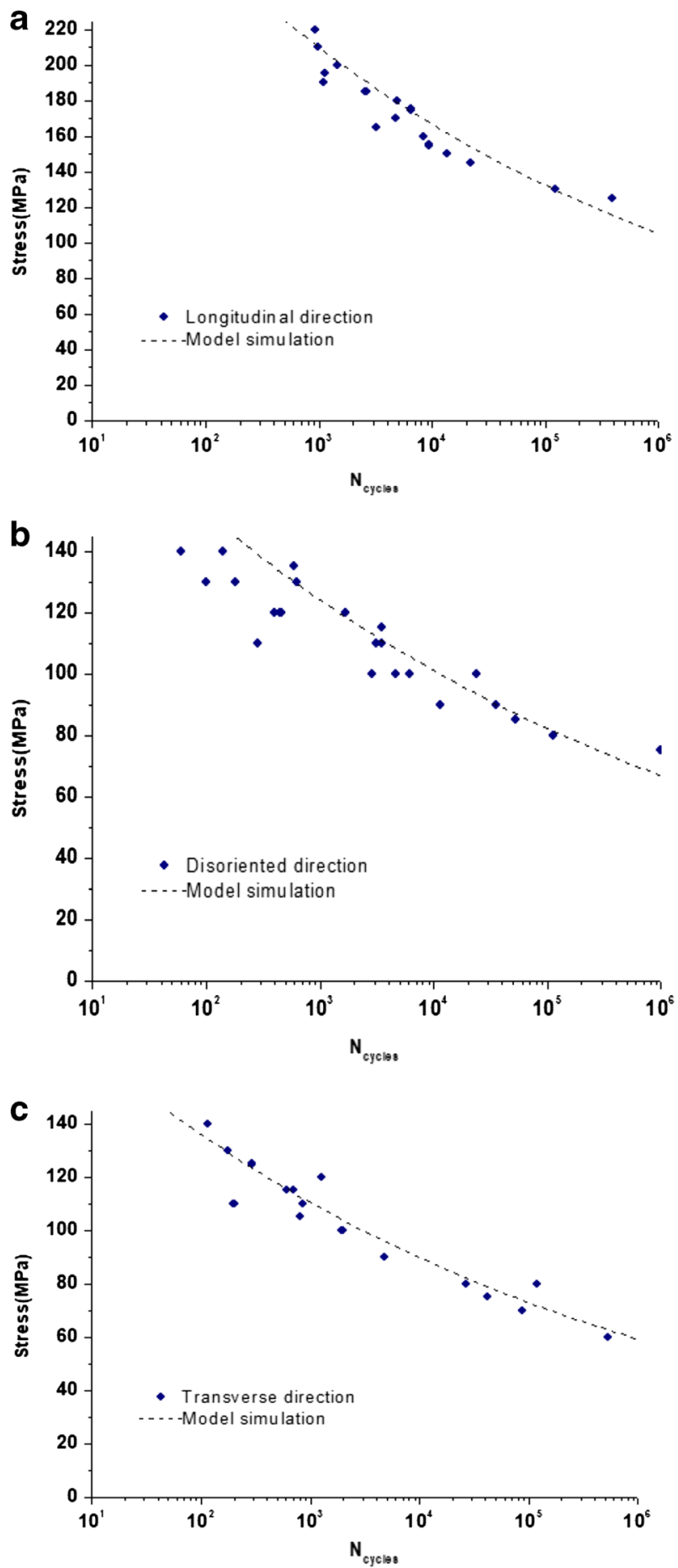

Fig. 10 Comparison of experimental-digital Wöhler curves (a) Transverse direction, (b) Disoriented, (c) Longitudinal direction (second approach) 
Once the model is identified, the monotonic-loading tensile test for any selected microstructure is modeled. The modeling of the microscopic damage is validated by the simulation of the curves of the evolution of the macroscopic damage as a function of the applied stress (D, $\sigma)$ for the chosen microstructure, where $\mathrm{D}$ is the damage parameter of Kachanov. The value of the $\mathrm{D}_{\mathrm{S}}$ macroscopic damage reached for stress $\sigma=\mathrm{S}$ is read on the curve resulting from model $(D, \sigma)$. After that, the corresponding number of break cycles NR is read directly on curve (D, $\mathrm{NR}$ ). We record the value pair (S, NR). These successive steps are repeated for other stress values $\mathrm{S}$ in order to establish the $\mathrm{S}-\mathrm{N}$ curve of the chosen microstructure.

The developed methodology is validated by comparison with the experimental results of the Wöhler curves obtained on A-SMC (Fig. 10).

\subsection{Comparison of Two Approaches}

The two proposed hybrid models fall under a common idea: Whatever the type of applied stress (monotonic or cyclic), the material goes through the same successive damaged states to final failure. The central idea of these two approaches is therefore to base the fatigue life prediction on the simulation results of damage under monotonic stress. Thus, both approaches use a micromechanical model to predict local damage to A-SMCs as a function of the microstructure. However, both models are distinguished by their methodologies. At this level, the two methods coincide well with the experimental results, so we can validate our approach. The first proposed methodology is also based on the experimental analysis and micromechanical modeling of the monotonous behavior to predict the fatigue-type loading life. However, unlike the second approach, the intrinsic relationship involves a microscopic scale. Indeed, the same damage states follow each other until failure, regardless of the type of loading. A state equation, based on micromechanical modeling linking a local damage rate to a monotonous loading macroscopic damage rate, can easily be generalized to a cyclic loading state. The final rupture occurs when the density of the micro cracks reaches a certain critical value. The S-N curve can therefore be estimated for all microstructure configurations. The suggested procedure is applied for three different microstructural configurations: $\mathrm{HO}-90^{\circ}, \mathrm{HO}-0^{\circ}$ and $\mathrm{RO}$. A very good experience-simulation correlation demonstrates the effectiveness of the proposed methodology. Note that the parameters to be identified are six, Five of them are directly determined by the micromechanical modeling under monotonous loading $\left(\alpha, \beta, \gamma, b i\right.$ and $\sigma_{i}^{s}$ ); the last parameter $(B i)$ has to be identified experimentally through some fatigue tests, which do not necessarily have to be carried out until rupture.

\section{Conclusion}

For the A-SMC material studied here, the dominant damage mechanism is interracial decohesion, which leads to the degradation of mechanical properties and to reduced rigidity. A formulation of a constitutive model of micromechanical damage is presented to predict the decrease in rigidity as a function of the number of fatigue cycles. This model is based on an interfacial quadratic criterion expressed in terms of local stress normal and tangential to the fiber-matrix interface. To evaluate the capacity of the model, three tests are considered in the set of experimental data. 
In this article, we have started by describing a new type of A-SMC composite material developed by our partner, PLASTIC OMNIUM, passing through the presentation of our common micromechanical model for both approaches. This model can translate a direct relationship between the successive states of damage at the macroscopic and microscopic scales. This relationship is subsequently considered intrinsic and independent of the type of loading: implicitly in the first proposed approach and explicitly in the second one.

Indeed, two phenomenological-micromechanical hybrid modeling approaches have been proposed. They are both based on micromechanical modeling, which allows the behavior of the studied material to be translated under monotonic loading, while considering the microstructure and the damage (fiber / matrix interface).

\section{References}

1. Degrieck, J., Van Paepegem, W.: Fatigue damage Modelling of fibre-reinforced composite materials. Review. Applied Mechanics Reviews. 54(4), 279-300 (2001)

2. Simoes, T., Octavio, C., Valença, J., Costa, H., Dias-da-Costa, D., Júlio, E.: Influence of concrete strength and steel fibre geometry on the fibre/matrix interface. Composites Part B. 122, 156-164 (2017)

3. Rolland, H., Saintier, N., Wilson, P., Merzeau, J., Robert, G.: In situ X-ray tomography investigation on damage mechanisms in short glass fibre reinforced thermoplastics: effects of fibre orientation and relative humidity. Composites Part B. 109, 170-186 (2017)

4. Mortazavian, S., Fatemi, A.: Effects of fiber orientation and anisotropy on tensile strength and elastic modulus of short fiber reinforced polymer composites. Composites Part B. 72, 116-129 (2015)

5. Roundi, W., El Mahi, A., El Gharad, A., Rebière, J.L.: Experimental and numerical investigation of the effects of stacking sequence and stress ratio on fatigue damage of glass/epoxy composites. Composites Part B. 109, 64-71 (2017)

6. Arif, M.F., Saintier, N., Meraghni, F., Fitoussi, J., Chemisky, Y., Robert, G.: Multiscale fatigue damage characterization in short glass fiber reinforced polyamide-66. Composites Part B. 61, 55-65 (2014)

7. G. KALAPRASAD, K. JOSEPH, S. THOMAS. Theoretical modelling of tensile properties of short sisal fibre reinforced low-density polyethylene composites. Journal of composite materials

8. JAYAMOL GEORGE, M. S. SREEKALA, and SABU THOMAS. A Review on Interface Modification and Characterization of Natural Fiber Reinforced Plastic Composites. POLYMER ENGINEERING AND SCIENCE, SEPTEMBER 2001, Vol. 41, No. 9

9. Laly, A.: Pothana, SabuThomas. G.Groeninckxc. The role of fibre/matrix interactions on the dynamic mechanical properties of chemically modified banana fibre/polyester composites. Composites Part A: Applied Science and Manufacturing. 37(9), 1260-1269 (September 2006)

10. Maya Jacob, Sabu Thomas, K.T. Varughese . Mechanical properties of sisal/oil palm hybrid fiber reinforced natural rubber composites. Composites Science and Technology Volume 64, Issues 7-8, June 2004, Pages 955-965

11. Thomas, S., Joseph, K.: S. K. Malhotra, Koichi Goda, M. S. Sreekala. Book polymer composites. Macroand Microcomposites. https://books.google.fr/books?hl=fr\&lr=\&id=et-RNth7xL8C\&oi=fnd\&pg=PR5 $\& d q=$ Prof.+Goda+et+al\&ots=ybY44foUhu\&sig=EddGG6qF5EibIXewEh6ocuaEupU\#v=onepage \&q\&f= false

12. Tamboura S, 1999. "Etude microstructurale et mécanique de l'endommagement en fatigue du matériau composite type SMC R42", Thèse de l'ENIT Tunis. 13 Juillet 1999

13. Bardia E, 2011. Approche cinétique du comportement en fatigue du polyaide 66 renforcé par $30 \%$ de fibres de verre

14. Khan, R., Alderliesten, R., Badshah, S., Benedictus, R.: Effect of stress ratio or mean stress on fatigue delamination growth in composites: critical review. Compos. Struct. 124, 214-227 (2015)

15. Andersons, J., Hojob, M., Ochiaic, S.: Empirical model for stress ratio effect on fatigue delamination growth rate in composite laminates. Int. J. Fatigue. 26(6), 597-604 (2004)

16. Kotik, H., Perez, I.J.: Frequency effect in short-beam shear fatigue of a glass fiber reinforced polyester composite. Int. J. Fatigue. 90, 116-124 (2016)

17. Eftekhari, M., Fatemi, A.: On the strengthening effect of increasing cycling frequency on fatigue behavior of some polymers and their composites. Experiments and modeling: International Journal of Fatigue. 87, 153166 (2016) 
18. Passipoularidis V, Brondsted P. Fatigue Evaluation Algorithms: Review. Roskilde: Danmarks Tekniske Universitet, Risø Nationallaboratoriet for Bæredygtig Energi 2010. (Denmark. Forskningscenter Risoe. Risoe-R; No. 1740(EN))

19. Sendeckyj GP. Chapter 10 - Life Prediction for Resin-Matrix Composite Materials. In: Reifsnider KL, éditeur. Composite Materials Series [Internet]. Elsevier; 1991 [cité 25 juin 2018]. p. 431-83. (Fatigue of Composite Materials; vol. 4)

20. Palumbo, D., De Finis, R., Giuseppe Demelio, P., Galiettiet, U.: A new rapid thermographic method to assess the fatigue limit in GFRP composites. Compos. Part B. 103, 60-67 (2016)

21. Rajaneesh, A., Satrio, W., Chai, G.B., Sridhar, I.: Long-term life prediction of woven CFRP laminates under three point flexural fatigue. Compos. Part B. 91, 539-547 (2016)

22. Jegou, L., Marco, Y., Le Saux, V., Calloch, S.: Fast prediction of the Wöhler curve from heat build-up measurements on short Fiber reinforced Plastic. Int. J. Fatigue. 47, 259-267 (2013)

23. Marco, Y., Huneau, B., Masquelier, I., Le Saux, V., Charrier, P.: Prediction of fatigue properties of natural rubber based on the descriptions of the cracks population and of the dissipated energy. Polym. Test. 59, 6774 (2017)

24. Serrano Abello, L., Marco, Y., Le Saux, V., Robert, G., Charrier, P.: Fast prediction of the fatigue behavior of short fiber reinforced thermoplastics from heat build-up measurements. Procedia Eng. 66, 737-745 (2013)

25. Masquelier, I., Marco, Y., Le Sauxa, V., Callocha, S., Charrier, P.: Thermal measurements on elastomeric materials: from the characterization of the dissipation gradients to the prediction of the fatigue properties. Procedia Eng. 66, 661-668 (2013)

26. Marco, Y., Masquelier, I., Le Saux, V., Charrier, P.: Fast prediction of the Wohler curve from thermal measurements for a wide range of NR and SBR. Rubber Chem Technol September. 90(3), 487-507 (2017)

27. Jain A, M Veas J, Straesser S, Van Paepegem W, Verpoest I, V. Lomov S . The Master SN curve approach A hybrid multi-scale fatigue simulation of short fiber reinforced composites. Composites: Part A 2015

28. Jain A, Van Paepegem W, Verpoest I, V Lomov S. A feasibility study of the master SN curve approach for short fiber reinforced composites. Int. J. Fatigue 2016; 91: 264-274

29. Laribi, M.A., Tamboura, S., Fitoussi, J., Tiébi, R., Tcharkhtchi, A., Ben Dali, H.: Fast fatigue life prediction of short fiber reinforced composites using a new hybrid damage approach: application to SMC. Composites Part B: Engineering, Volume. 139(15), 155-162 (April 2018)

30. Jain A, M Veas J, Straesser S, Van Paepegem W, Verpoest I, V. Lomov S . The Master SN curve approach A hybrid multi-scale fatigue simulation of short fiber reinforced composites. Composites: Part A 2015

31. Guo, G., Fitoussi, J., Baptiste, D.: A sequential and biaxial tensile loading test to investigate the damage behaviour in a random short Fiber SMC composite. Anal. Compos. AMAC. 3, 41-42 (1995)

32. Guo, G., Fitoussi, J., Baptiste, D.: Optimisation of a Failure Criterion for the Short-Fiber Reinforced Composites Materials by the Finite Element Analysis Using a Damage Micromechanics Model, pp. 675687. Peking University Press, Progress in Advanced Materials and Mechanics (1996)

33. G. Guo, J. Fitoussi, and D. Baptiste, Extension of Successive Iteration Method in the Homogenization of a Random Short-Fiber Reinforced Composite, Microstructures and Mechanical Properties of New Engineering Materials, Proc. 2nd IMMM'95, International Academic Publishers, 1995, p 15-21

34. Guo, G., Fitoussi, J., Baptiste, D.: Determination of Tridimensional Failure Criterion at the Fiber/Matrix Interface at an Organic Matrix and Discontinuous Reinforced Composite, JNC9, pp. 213-222. J.P. Favre and A.Vaurin, Ed, AMAC, St. Etienne, France (1994)

35. Derrien, K., Fitoussi, J., Baptiste, D.: Prediction of the effective damage properties and failure properties of nonlinear anisotropic discontinuous reinforced composites. Comput. Methods Appl. Mech. Eng. 185, 93107 (2000)

36. Le Pen, E., Baptiste, D., Hug, G.: Multi-scale fatigue behaviour Modelling of Al-A12O3 short fibre composites. Int. J. Fatigue. 24, 205-214 (2002)

37. Jendli Z., Meraghni F., Fitoussi J., Baptiste D., «Multi-Scales Modelling of Dynamic Behavior for Discontinuous Fiber SMC Composites», Composites Science Technology -69 (2009) 97-103, 2009

38. Mori T., Tanaka K., «Average Stress in Matrix and Average Elastic Energy of Materials with Misfitting Inclusions » Acta Metall 1973; 21:571-4, 1973

39. Shirinbayan, M., Fitoussi, J., Meraghni, F., Surowiec, B., Bocquet, M., Tcharkhtchi, A.: High strain rate visco-damageable behavior of advanced sheet molding compound (A-SMC) under tension. Compos Part B Eng. 3670(82), 30-41 (2015)

40. M. Shirinbayan a, J. Fitoussi a, M. Bocquet a, F. Meraghni b, B. Surowiec c, A. Tcharkhtchi. Multi-scale experimental investigation of the viscous nature of damage in Advanced Sheet Molding Compound (ASMC) submitted to high strain rates Composites Part B 115 (2017) 3e13

41. Benveniste, Y: A new approach to the application of Mori-Tanaka's theory. Mech. Mater. 6, 147-157 (1987) 
42. Mura T., Cheng P.C, The elastic field outside an ellipsoidal inclusion. J. Appl. Mech. 1977 : 591-594

43. Eshelby J.D, The determination of the elastic field of an ellipsoidal inclusion and related problems, Proc. Roy. Soc. London, A 241, 1957, p. 376-396

44. Taya, M.: Mura T, on stiffness and strenght of an aligned short-fiber reinforced composite containing fiberend cracks under uniaxial applied stress. J. Appl. Mech. 48, 361-367 (1981)

45. Morozov, E.V., Morozov, K.E.: Selvarajalu V, Damage model development for SMC composites. Compos. Struct. 62, 375-380 (2003)

46. Tamboura, S., Sidhom, H., Baptiste, H., Fitoussi, J.: Evaluation de la tenue en fatigue du composite SMC R42. Mater. Tech. 3-4 (2001)

47. Shirinbayan, M., Fitoussi, J., Abbasnezhad, N., Meraghni, F., Surowiec, B., Tcharkhtchi, A.: Overall Mechanical Characterization of a Low Density Sheet Molding Compound (LD-SMC): Multi-Scale Damage Analysis and Strain Rate Effect. Composites Part B, Engineering (2017)

\section{H. Ayari ${ }^{1,2} \cdot$ J. Fitoussi ${ }^{1} \cdot$ A. Imaddahen ${ }^{1} \cdot$ S. Tamboura $^{2} \cdot$ M. Shirinbayan ${ }^{1} \cdot$ H. Ben Dali $^{2} \cdot$ A. Tcharkhtchi ${ }^{1}$}

J. Fitoussi

joseph.fitoussi@ensam.eu

A. Imaddahen

mohamed-amine.imaddahen@ensam.eu

S. Tamboura

sahbi.tamboura@gmail.com

M. Shirinbayan

mohammadali.shirinbayan@ensam.eu

H. Ben Dali

hachmi.bdaly@gmail.com

A. Tcharkhtchi

abbas.tcharkhtchi@ensam.eu

Arts et Métiers ParisTech, PIMM - UMR CNRS 8006, 151 Boulevard de l'Hôpital, 75013 Paris, France

2 University of Sousse, Ecole Nationale d'Ingénieurs de Sousse, LMS, Pôle technologique, Route de

Ceinture, 4054 Sousse, Tunisia 